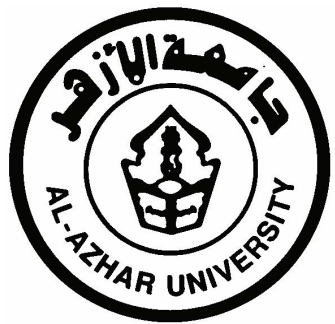

$$
\begin{aligned}
& \text { جامعست الأزهــــر } \\
& \text { كليـت أصــول الديـن } \\
& \text { والدعوة الإسلاميتَ بالمنوفيت }
\end{aligned}
$$

هوض النبي" صلى الالهُ عليه وسلم، وصفتُه

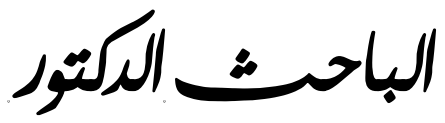

هشام منصور عبد الحي مشمد حسن

أستاذ الحديث وعلومهه (المساعد) بكليةٍ الدراسات الإسلاميةٍ

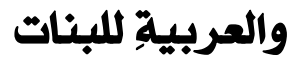

بالزفازيق - جامعة الأزهر 



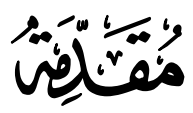

الحمدُ لله، و الصلاةُ و السلامُ على سيدنا رسول اله، و أثنهُُ أن لا إله إلا الله، و أثنهد أن سيدَنا محمداً عبدُه ورسولُه، ولهُ

\section{وريع/6666 66}

تتجلى رحمةُ الله تعالى يومَ القيامة حين تدنو الثمسُ من الرؤوس، ويتمكنُ

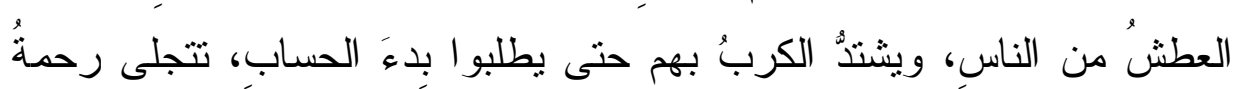

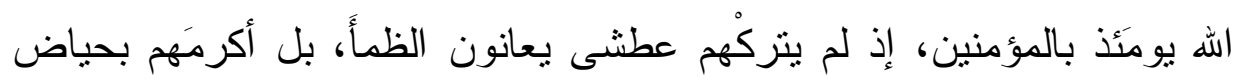

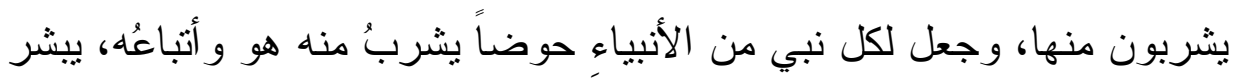

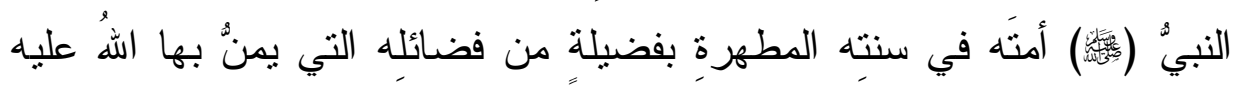

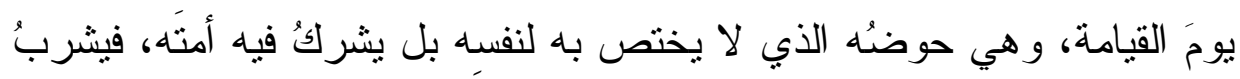

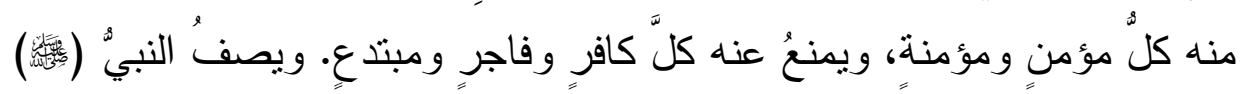

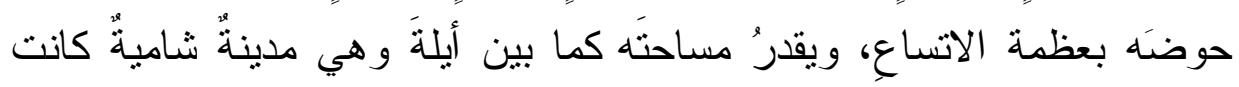

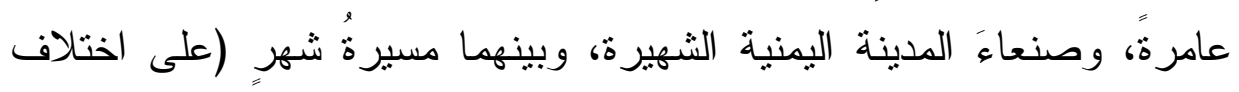
الروايات في سعته)، و أن عددَ كؤوسَه كعددِ نجومِ السماءِ، إما مطابقة أو دلالة

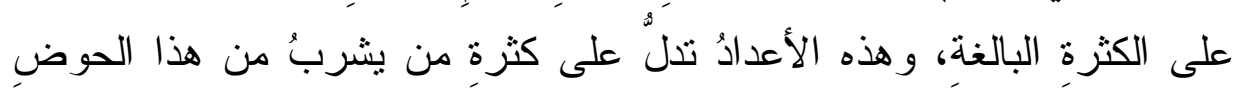
النبوي المباركَ، الذَي منَ شربَ منه شربةً لا يظماًُ بعدها أبداً.

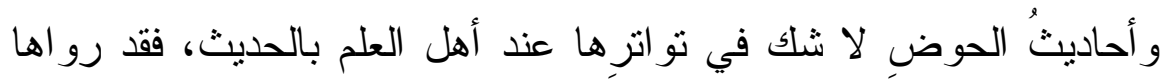

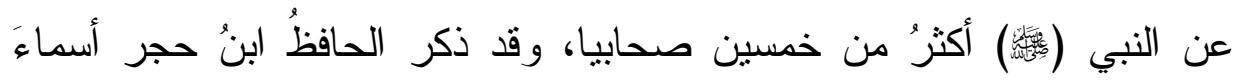
رواة أحاديثِه من الصحابة، ونَقَلَ عن القرطبي فقال: (وقال القرطبيهّ في المفهم

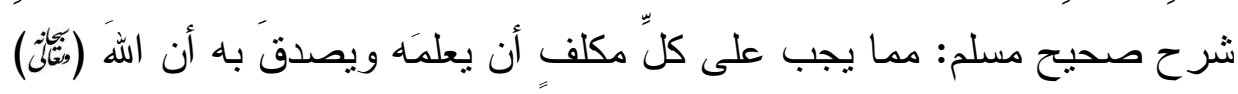




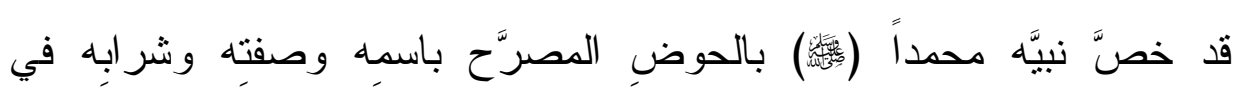

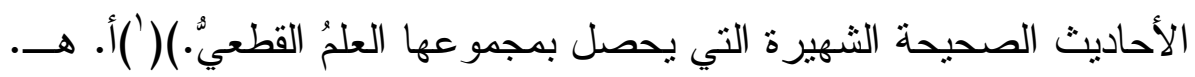

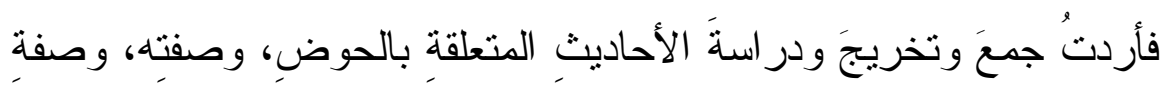

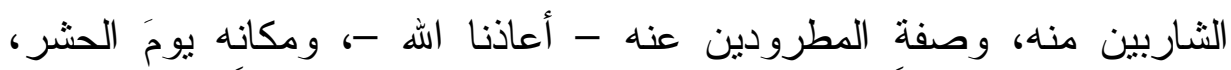
وكيفية الثرب منه. و اقتصرتُ على الروايات الواردة في الكتب الستة فقيها ما ولها يفي بالغرضِ. فاستخرتُ الله تعالى وقسمتُ بحثي هذا إلى مقدمة وسبعةِ مباحثَ

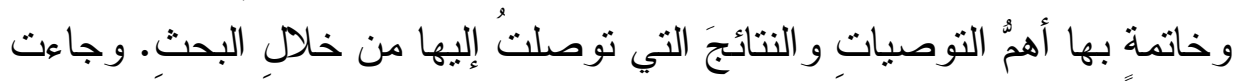
النتائجُ بفضِ الله تعالى على درجةٍ كبيرةٍ من الأهميةِ التي ينبخي لكل مسلم أن يعِيَها. أما المقدمةُ: فقيها تحدثتُ فيها عن أهميةٍ الموضو ع ومنهجِه. المبحث الأول: المبحث الأول: إثبات حوض النبي (: ومن أنكره، ووجوده الآن.

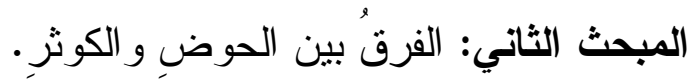

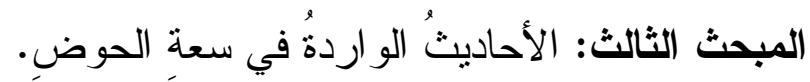
المبحث الر ابع: وصفُ الحوض و آنيته.

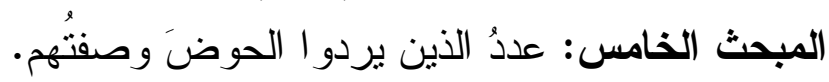
المبحث السادس: صفةُ المطرودين عن الحوضِ. المبحث السابع: مكانُ الحوضِ يومَ القيامة. الخاتمة: وبها أهم النتائج و التوصيات التي توصلت إليها من خلان البحث. وكان منهجي في البحث أن لا أترجم لرجال إبناد الحديث إذا كان في لهني

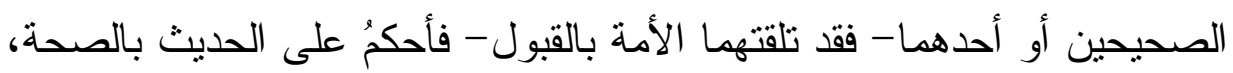




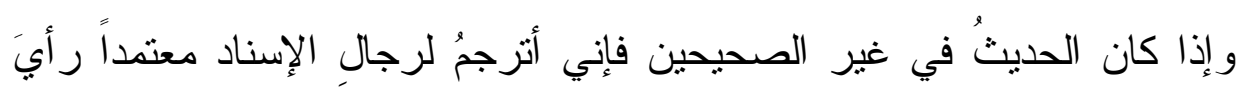

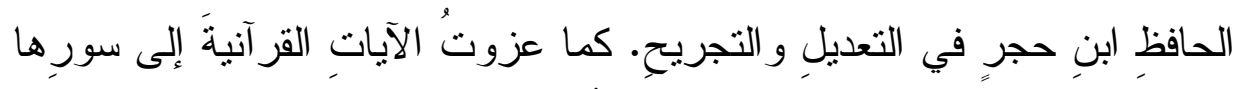

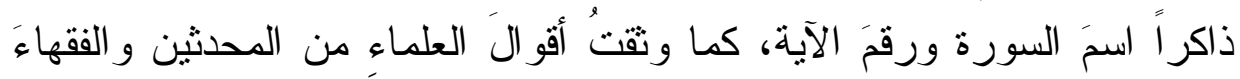

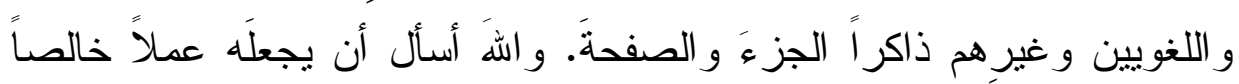

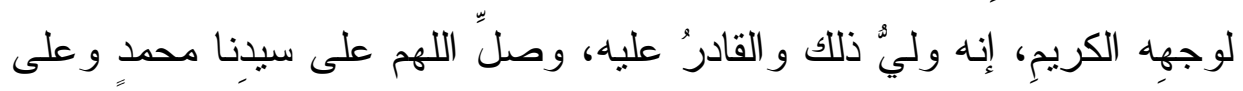
آلَِ وصحبِه وسلمَ.

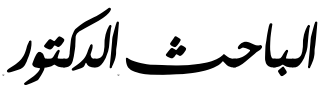

هشام منصور عبد الهي هممد حسن 


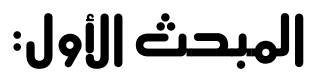

\section{وفودوه الآن}

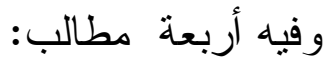

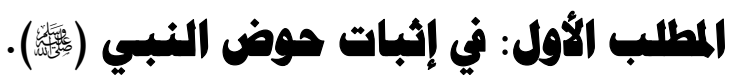

الإيمان بالحوض واجب، وهو عقيدة أهل السنة والجماعة.

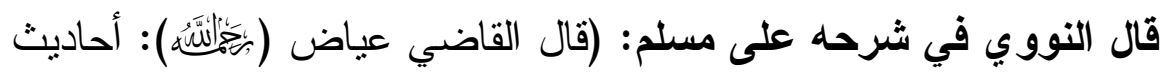
الحوض صحيحة و الإيمان به فرض و التصديق به من الإيمان وهو على ظلى ظاهره

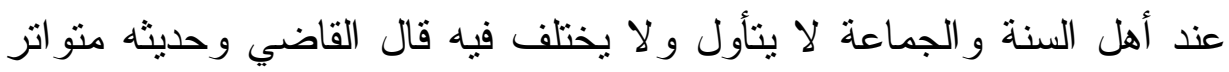

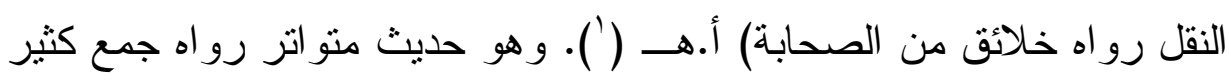

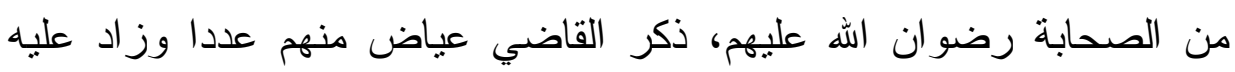
النووي وزاد عليهما الحافظ ابن حجر حتى وصل عدد رواته عند البعض الهض مايزيد على ثمانين نفسا. قال ابن حجر في الفتح: (فجميع من ذكرهم هُ عياض

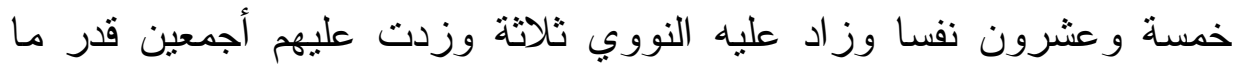

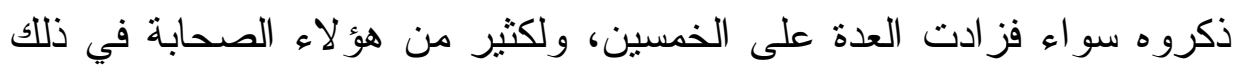
زيادة على الحديث الواحد كأبي هريرة و أنس و وابن عباس ولى وأبي سعيد و وعبد الله

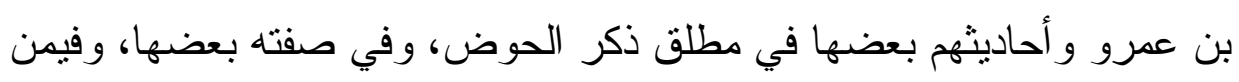
يرد عليه بعضها، وفيمن يدفع عنه بعضها وكذللك في الأحاديث التي أوردها

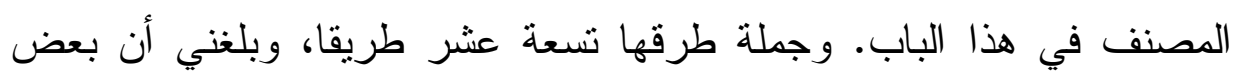
المتأخرين وصلها إلى رواية ثمانين صحابيا) أ.هــ(").

$$
\begin{aligned}
& \text { (1) شرح النووي على صحيح مسلم } 10 \text { (1) }
\end{aligned}
$$

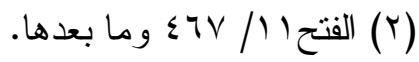


الحيث الأول: أخرج الإمام البخاري في صحيحه بسنده عَنْ عَبْدِ اللَّهَ، عَنِ

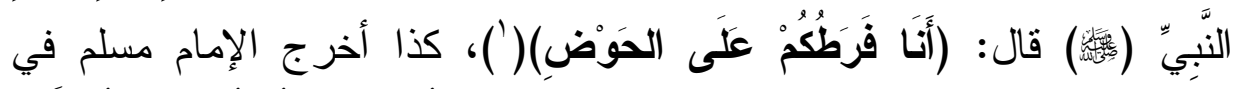

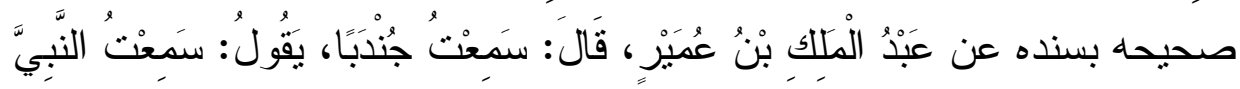

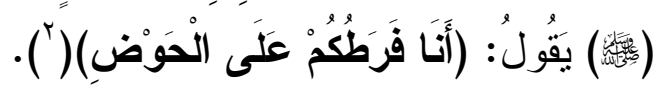

الحديث الثاني: أخرج الإمام البخاري في صحيحه بسنده عَنْ أَنَسِ بْنِ

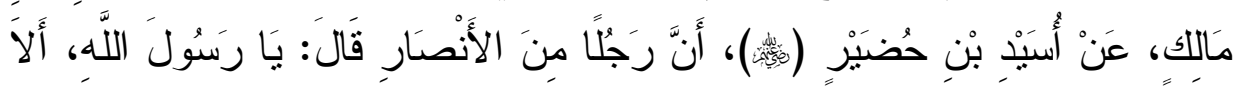

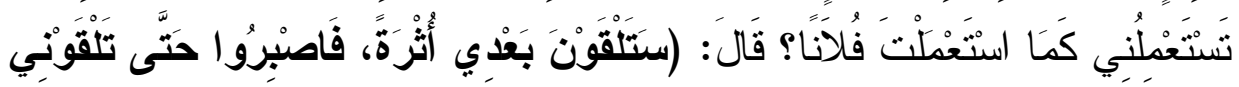
عَلَى الحَوْضِ)(") ومن طريق البخاري هذا وبسنده أخرجه الترمذي في سننه

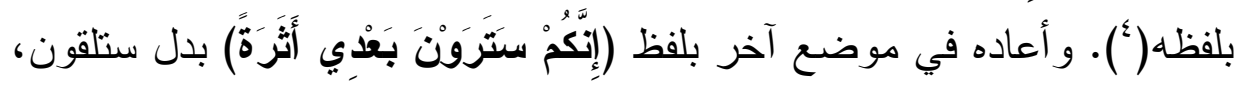

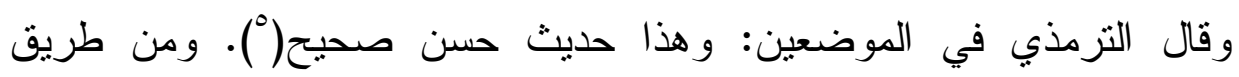
البخاري وسنده ولفظه هذا أخرجه النسائي في سننه( ولَ).

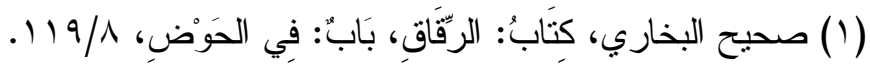

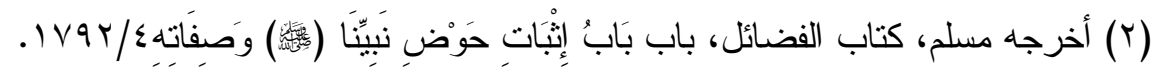

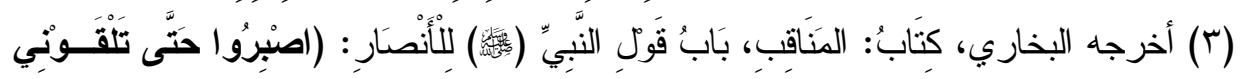

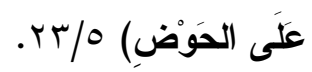

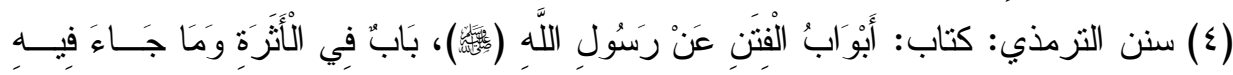

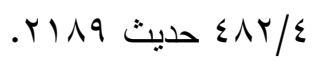

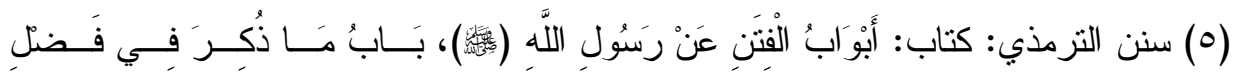

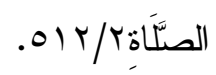

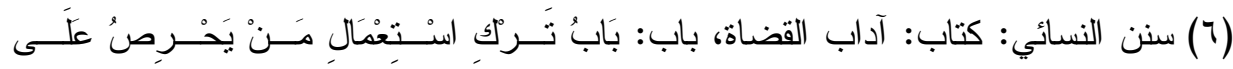

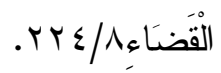
$-V-$ 


\section{حوضُ النبيٌْ صلى اللهُ عليه وسلمَ، وصفثه من خلالِ الكتبِ الستِِ}

الحديث الثالث: أخرج الإمام البخاري في صحيحه بسنده، عَنْ أَبِي هُرَيْرَةً

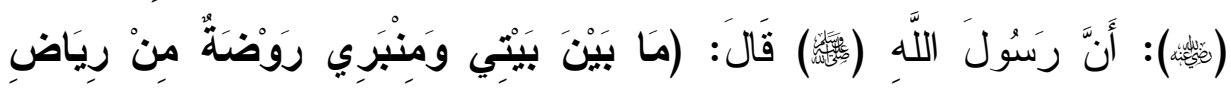
الجَنَّة، وَمَنْبَرِي عَلَى حَوْضِي)( ').

الحديث الرابع: أخرج ابن ماجة في سننه لفظ الحديث الأول وفيه زيادة،

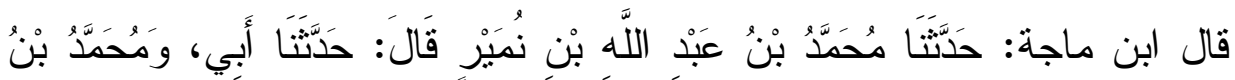

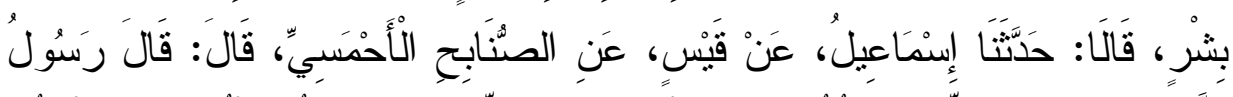

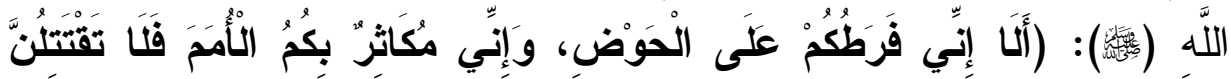

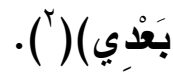

\section{وبال إسناد ابن مابة}

1 - محمد ابن عبد الله ابن نمير الهمداني: بسكون الميم الكوفي أبو عبد

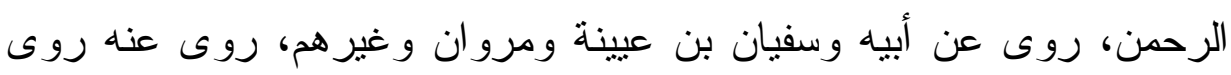

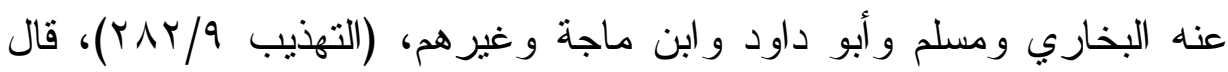
ابن حجر: ثقة حافظ فاضل من العاثرة مات سنة أربع وثلاثثن ومائتين

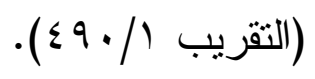

r - عَبْدِ اللَّهِ بن نمير الهمداني أبو هشام الكوفي: روى عن والأعمش ويحيى بن سعيد و الأوز اعي و غيرهم، و عنه أبو خيثمة ويحيى بن يحيى و علي بن المديني وغير هم (التهذيب OV/T)، قال ابن حجر : ثقة صاحب وديث ديث من

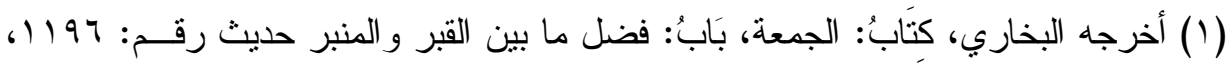
$.7) / r$

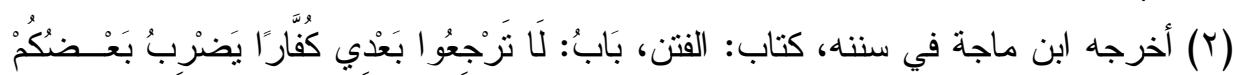

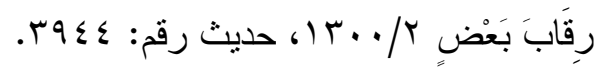


أهل السنة من كبار التاسعة مات سنة تسع وتسعين ومائة وله أربع وثمانون،

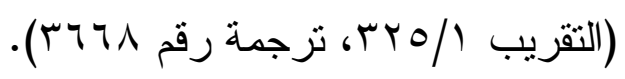

r - محمد بن بشر بن الفرافصة بن المختار الحافظ العبدي أبو عبد الله

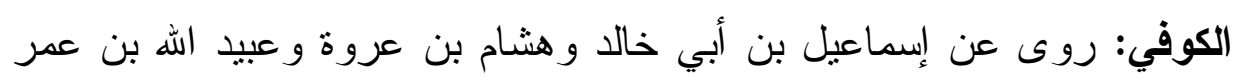
العمري وغيرهم، وروى عنه علي بن المديني و أبو بكر بن أبي شيبة و إسحاق بن

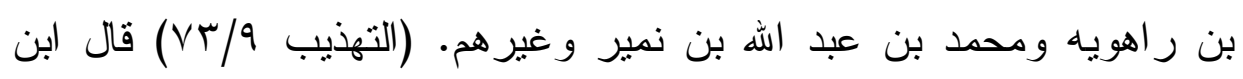

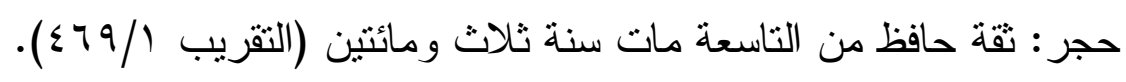
ع- إسماعيل بن أبي خالد الأحمسي: روى عن أبيه و أبي جحيفة و عبد الله بن أبي أوفى وعمرو بن حريث وأبي كاهل وهؤلاء صحابة، وعن زيد بن وهب ومحمد بن سعد وأبي بكر بن عمارة بن رويبة وقيس بن أبي حازم-

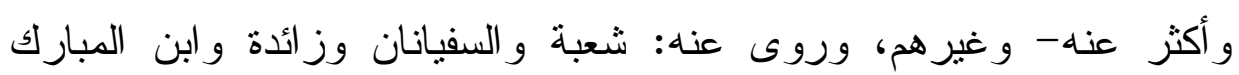

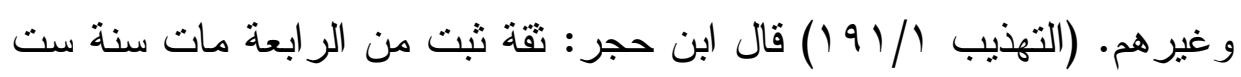

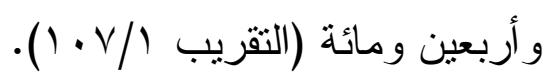

هـ قيس ابن أبي حازم: واسمه حصين بن عوف ويقال عوف بن عبد الحارث ويقال عبد عوف بن الحارث بن عوف البجلي أبو عبد الله الكوفي بي بن الأحمسي، روى عن: المغيرة بن شعبة و الصنابح بن الأعسر ودكين بن سعيد وغيرهم. وروى عنه: روى عنه إسماعيل بن أبي خالد وبيان بن بشر و المغيرة

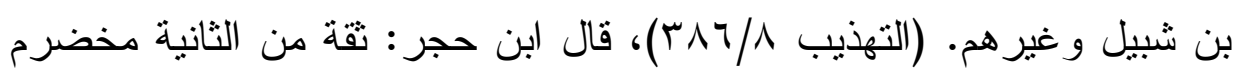

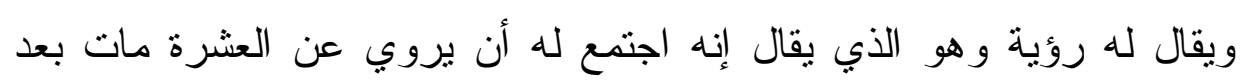

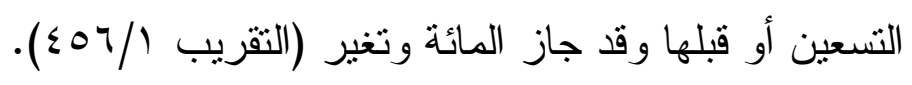


צ - الصنَُّبِح الْأَحْمَسِيِ: اسمه الصنابح بضم أوله ثم نون وموحدة ومهملة ابن الأعسر الأحمسي صحابي سكن الكوفة ومن قال فيه الصنابحي فقد وهم.

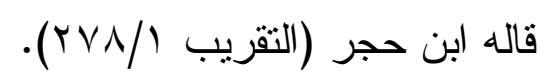
درجة الإسناد: إسناده صحيح وعبدالله بن نمير تابعه محمد بن بشر العبدي.

\section{التمايق على الروايات السابقة:}

تعريف الحوض: قال الأزهري: (قَالَ اللَّيْث: الحَوْضُ مَعْرُوف، والجميع

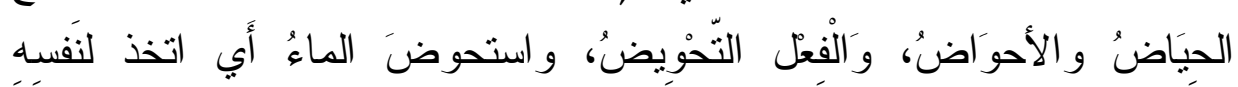

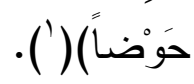

معنى فرطكم قال النووي: (قال أهل اللغة الفرط بفتح الفاء والراء و الفارط هو الذي يتقدم الوارد ليصلح لهم الحياض و الدلاء ونحوها من أمور الاستقاء

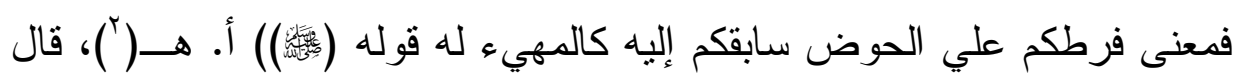
ابن الأثير: فيه 》أنا فرطكم على الحوضه أي متقدمكم إليه. يقال: فرط يفرط، فهو فارط وفرط إذا تقدم وسبق القوم ليرتاد لهم الماء، ويهيئ لهم الداء الاء

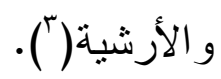

معنى أثرة: قال ابن الأثثر: فيه قال للأنصار : إنكم ستلقون بعدي أثزة

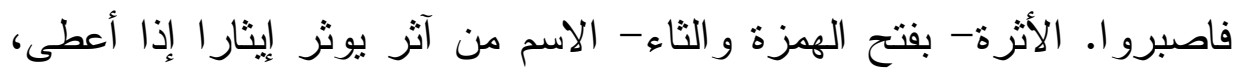

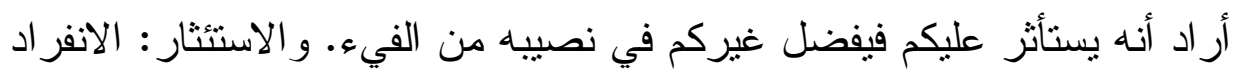

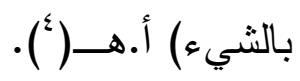

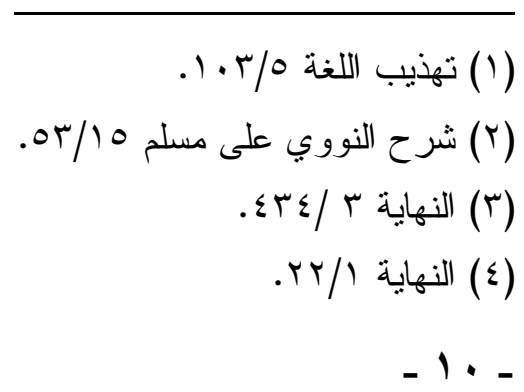




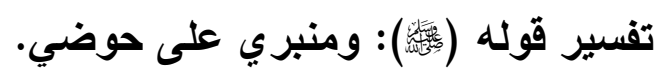

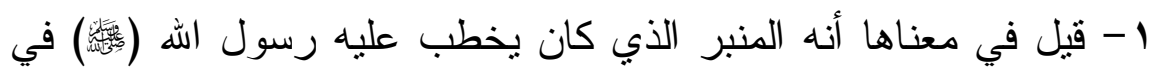
الدنبا، ولعل دليلهم حديث عند النسائي و الطبر اني و الحاكم و البيهقي، تارة يروى مرفوعا وتارة يروى موقوفا وكلها روايات ضعيفة. ورواية النسائي أصح

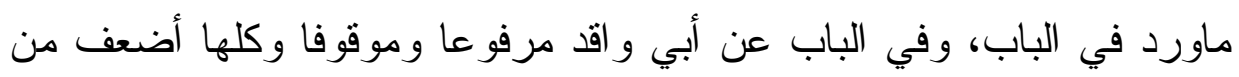

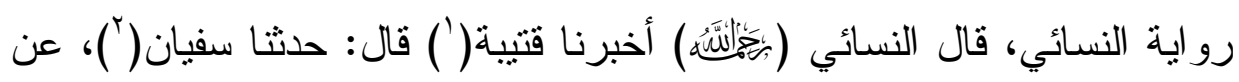

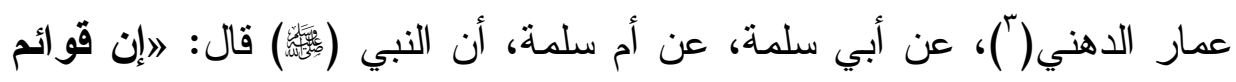
منبري هذا رواتب في الجنةه() و الحديث فيه عمار الدهني: صدوق يتشيع كما قال ابن حجر وقول ابن حجر أقل ما ذكر فيه.

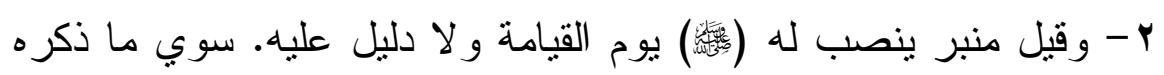
ابن حجر في الفتح ولم ينسبه لأي من العلماء. ب- وقيل قصد المنبر النبوي الثريف في الدنيا يورد صاحبه إلى الحوض. و الأقوال الثثلاثة ذكرها ابن حجر في الفتح، قال ابن حجر : (و أما قوله ومنبري

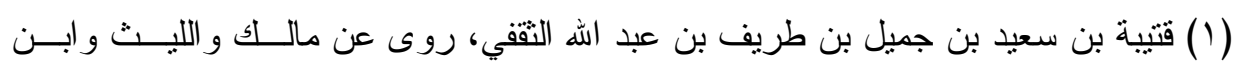

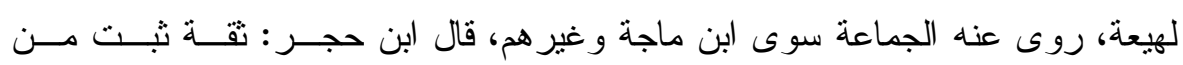

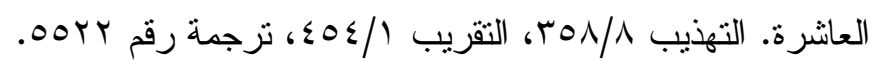

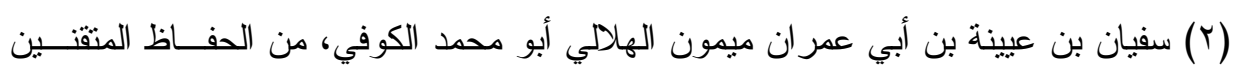

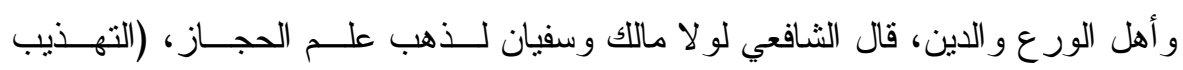

$$
\text { .) (1) } V, \varepsilon / \varepsilon
$$

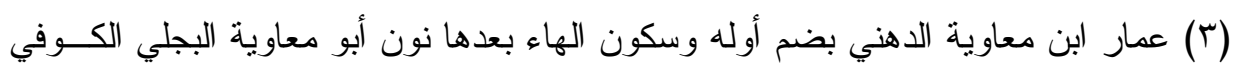

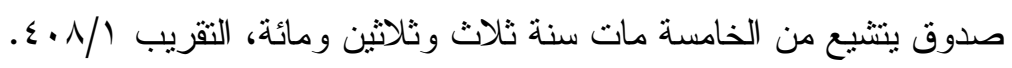

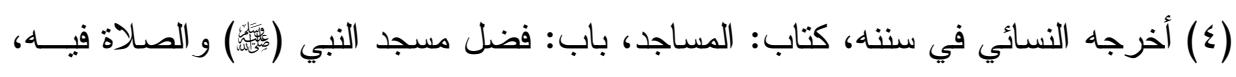
ro/r 
على حوضي أي ينقل يوم القبامة فينصب على الحوض وقال الأكثر المراد منبره بعينه الذي قال هذه المقالة وهو فوقه وقيل المر اد المنبر الذي يوضع له

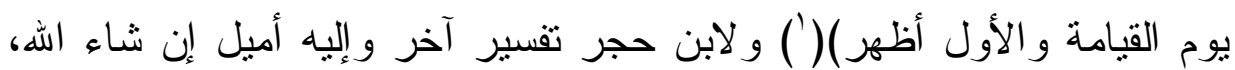
قال ابن حجر: وقيل معناه أن قصد منبره و الحضور عنده لملازمة الأعمال الصالحة يورد صاحبه إلى الحوض. ويقتضى شربه منه و الله أعلم) أ.هــ( (ب).

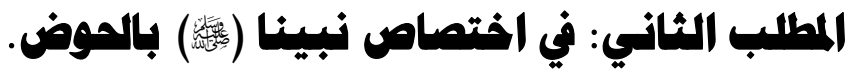

\section{أقول وبالله التوفيق:}

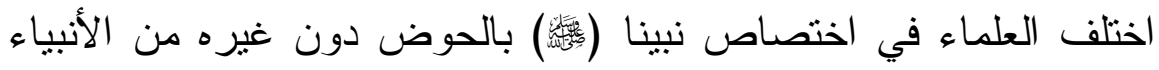
وسبب هذا الاختلاف حديث التزمذي وابن أبي الدنيا و الطبر اني مرفوعا عن

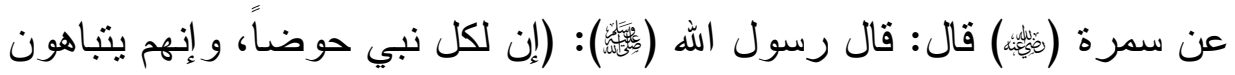
أيهر أكثر واردة، و إني أرجو أن أكون أكثزهم) - وسيأتي تخريجه في هذا المطلب - فقد اختلف في وصل هذا الحديث وإرساله. فالمرسل أخرجه ابن أبي الانيا بسند صحيح عن الحسن، فمَن يعمل بالمرسل من العلماء، فقد رأى أن وان

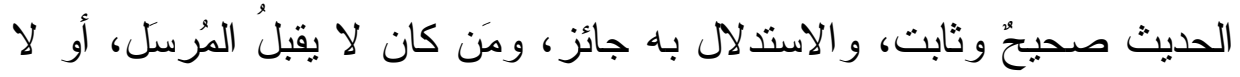

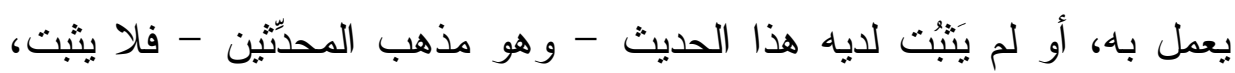

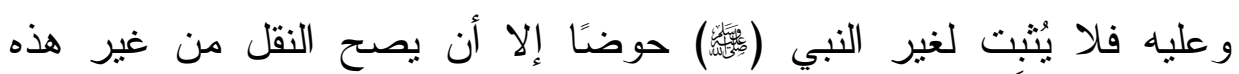
الطريق، ولم يصح النقل فيما وقفت عليه. فالحديث إذا وجدته موصولا كان في سنده لين، ووقع هذا عند الترمذي من حديث سمرة مرفوعا، وعند الطبر اني من حديث سمرة مرفو عا، و عند ابن أبي الدنيا من حديث أبي سعيد مرفو عا.

$$
\begin{aligned}
& \text { (1) فتح الباري ؟/. . 1. } \\
& \text { (r) المصدر السابق. }
\end{aligned}
$$


و الحاصل أن من صحح الحديث من العلماء (ممن يرى العمل بالمرسل)

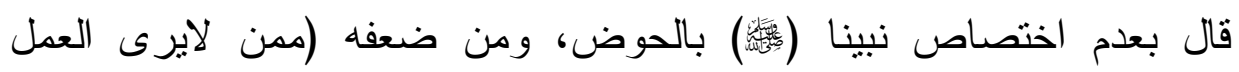

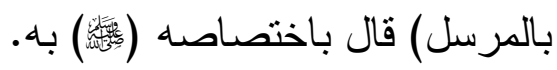

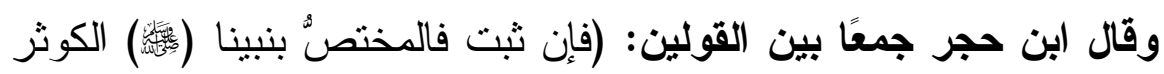
يصب ماؤه في حوضه، فإنه لم ينقل نظيره لغيره، فوقع الامتنان عليه به في

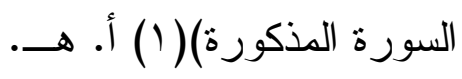
قال الحافظ ابن حجر: (وقد اثتهر اختصاص نبينا (إ) أخر ج الترمذي من حديث سمرة رفعه إن لكل نبي حوضا و أثنار إلى أنه اختلف في وصله وإرساله وأن المرسل أصح. قلت (القائل ابن حجر): و المرسل أخرجه ابن أبي الدنيا بسند صحيح عن الحسن، قال: قال رسول الله (ئس لكل نبي حوضا وهو قائم على حوضه بيده عصا يدعو من عرف من أمته إلا أنهم يتباهون أيهم أكثر تبعا وإني لأرجو أن أكون أكثرهم تبعا، وأخرجه الطبراني من وجه آخر عن سمرة موصولا مرفوعا مثله وفي سنده لين،

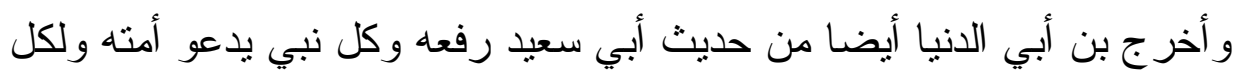
نبي حوض فمنهم من يأتيه الفئام ومنهم من يأتيه العصبة ومنهم من يأتيه الو احد

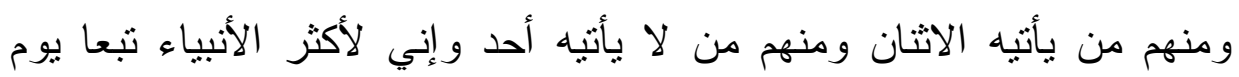

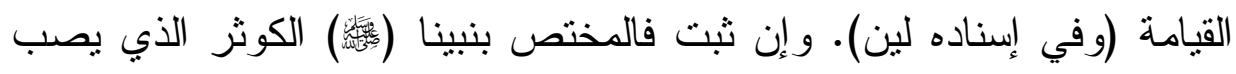
من مائه في حوضه فإنه لم ينقل نظيره لغيره ووقع الامتتان عليه به في السورة

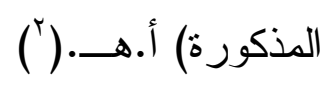

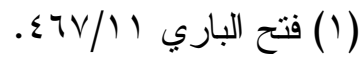

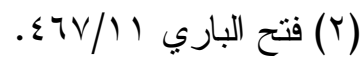


ونقل ابن حجر عن القرطبي: (قال القرطبي في المفهم تبعا للقاضي عياض في غالبه مما يجب على كل مكلف أن يعلمه ويصدق به أن الله (ونكلي) قد

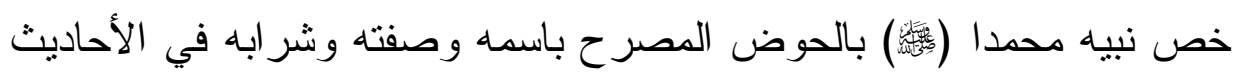
الصحيحة الثهيرة التي يحصل بمجموعها العلم القطعي إذ روى ذلك عن النبي

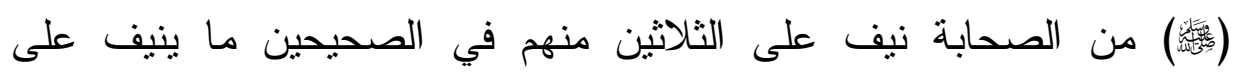

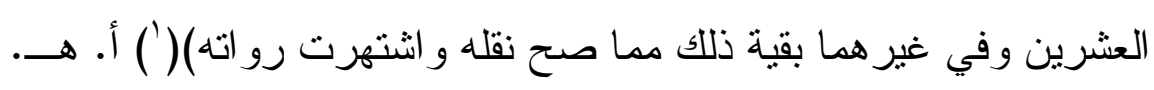
قال الباحث: كلام القرطبي الذي نقله ابن حجر وكلام القاضي عياض فيه

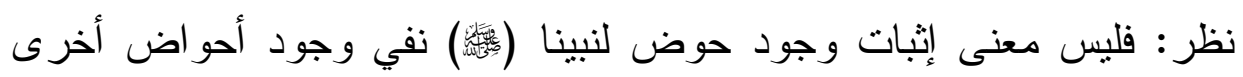
لرسل آخرين و لا حرج على فضل الله، فلم يثبت في نص صريح لا صحيح و لا

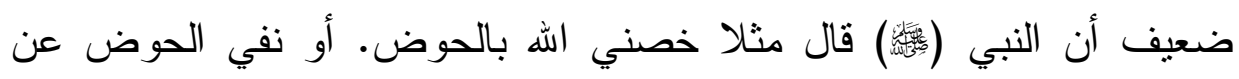

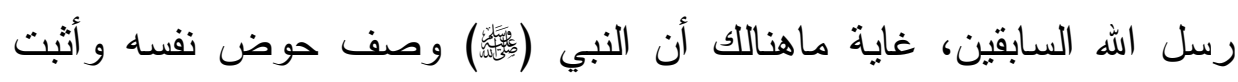

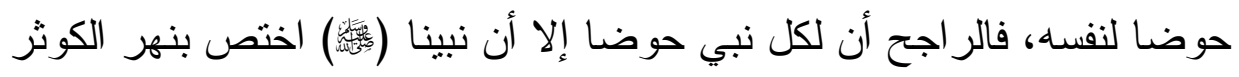
الذي يصب ماؤه في حوضه، و الكوثر ليس الحوض - كما سيأتي في المطلب

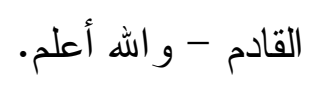

ومع دراسة الحديث الأي أثبت أن لكل نبي حوضا:

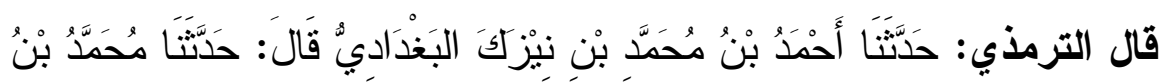

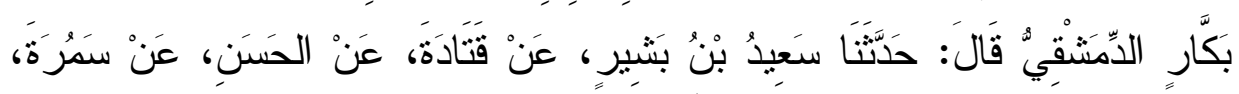

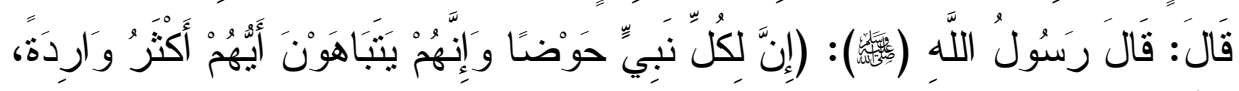

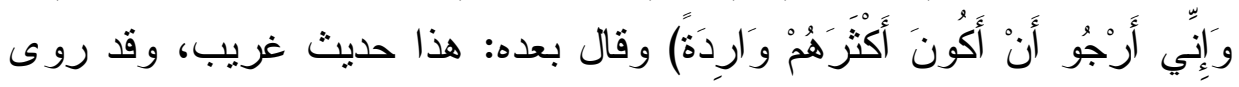

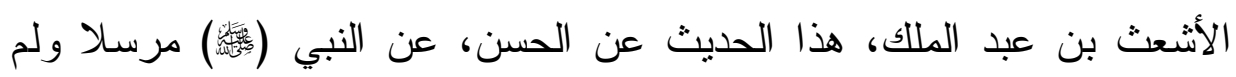
يذكر فيه عن سمرة وهو أصح. 
أخرجه الترمذي في سننه، كتاب: أبو اب صفة القيامة و الرقائق و الورع

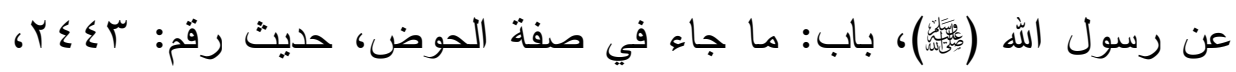

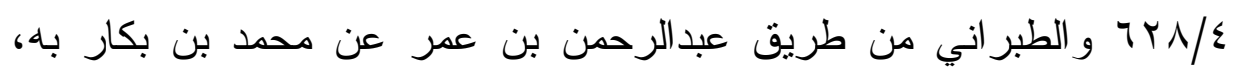

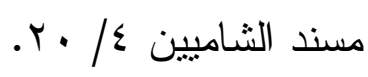

\section{رجال الإسناد: - إن}

1- أحمد ابن محمد ابن نيزك بكسر النون بعدها تحتانية ساكنة ثم زاي مفتوحة ثم كاف ابن حبيب البغدادي أبو جعفر الطوسي. روى عن: أسود بن بن بن بن عامر شاذان ومحمد بن بكار وأبي أحمد الزهري وغيرهم. وروى عنه الترمذي و إير اهيم الحربي و ابن أبي عاصم و ابن صاعد وغير هم. قال بن عقدة: في أمره نظر. (التهذيب (VV/ )، قال ابن حجر: صدوق في حفظه شيء من

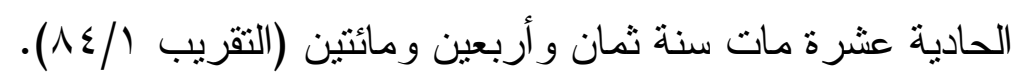
r- محمد بن بكار بن بلال العاملي أبو عبد الله الدمشقي القاضي. روى عن: سعيد بن بشير وسعيد بن عبد العزيز ومحمد بن راثد المكحولي وغيرهم. روى عنه: أبناه الحسن و هارون و ابن ابنه الحسن بن أحمد بن محمد وأحمد بندي

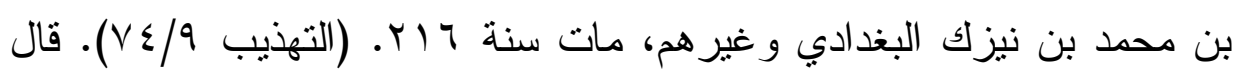
ابن حجر : صدوق من التاسعة مات سنة ست عشرة ومائة وله أربع وسبعون

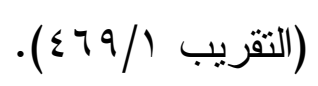

r- سعيد بن بشير الأزدي ويقال البصري مولاهم أبو عبد الرحمن ويقال أبو سلمة الثامي أصله من البصرة ويقال من و اسط روى عن قتادة و الزهري هري لازدي ولئ و عمرو بن ديناروغير هم. وروى عنه: بقية وأسد بن موسى و ابن عبينة و عبد

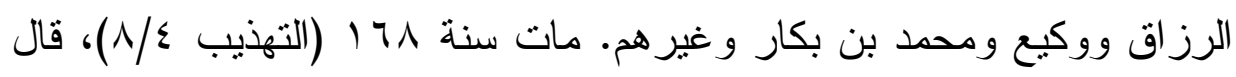


ابن حجر: ضعيف من الثامنة مات سنة ثمان أو تسع وستين ومائة (التقريب . (r $r \leqslant /)$

ع- قتادة ابن دعامة ابن قتادة السدوسي أبو الخطاب البصري ثقة ثبت يقال ولد أكمه وهو رأس الطبقة الرابعة مات سنة بضع عشرة ومائة (التقريب . $(\leqslant r o /)$

0- الحسن الحسن ابن أبي الحسن البصري و اسم أبيه بسار بالتحتانية

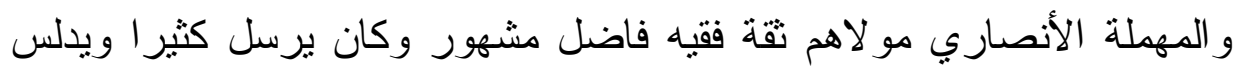
قال البزار كان يروي عن جماعة لم يسمع منهم فيتجوز ويقول حدثنا وخطبنا

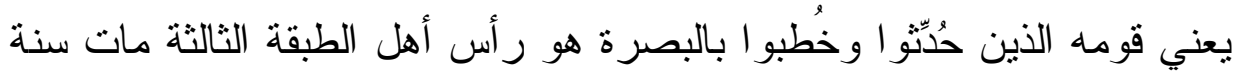

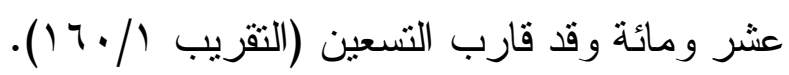
7- سمرة ابن جندب ابن هلال الفزاري حليف الأنصار صحابي مشهور

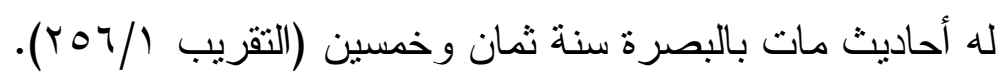
درجة الإسناد : إسناد ضعيف فيه سعيد بن بشير (ضعيف).

\section{الامباب الثالث: فيمن أنكر الموض}

أجمع السلف وأهل السنة من الخلف على إثبات الحوض، و أنكرت ذللك طائفة من المبتدعة وأحالوه على ظاهره و غلوا في تأويله من غير استحالة عقلية ولا عادية تلزم من حمله على ظاهره وحقيقته و لا حاجة تدعو إلى تأويله فأنكره الخوارج وبعض المعتزلة وممن كان ينكره عبيد الله بن زياد أحد أمر اء

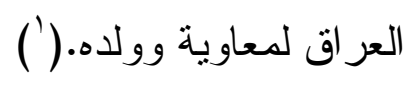


قال أبو داوودد: حدثا مسلم بن إبر اهيم، حدثنا عبد السلام بن أبي حازم أبو

طالوت، قال: شهدت أبا برزة دخل على عبيد الله بن زياد(')، فحدثي فلان (هذه مقولة أبي داود) سماه مسلم (أي مسلم بن إبر اهيم شيخ أبي داود) وكان في بردي السماط - فلما ر آه عبيد الله قال: إن محمديكم هذا الدحداح، فقهمها الثيخ، فقال:

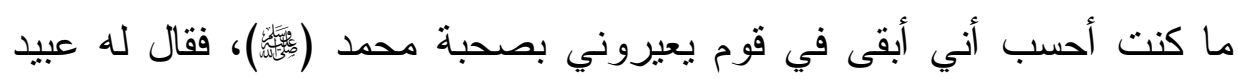

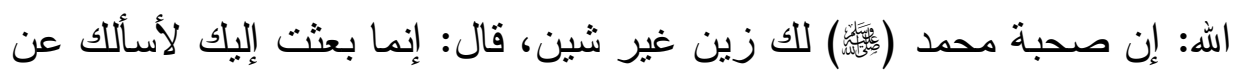
الحوض، سمعت رسول الله (ئس

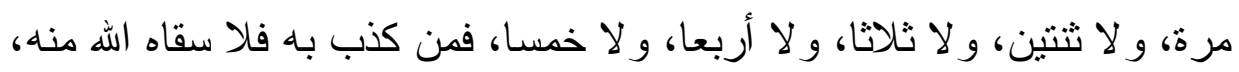
ثم خر ج مغضباه

(1) أمير العر اق، أبو حفص. ولي البصرة سنة خمس وخمسين، وله ثثتان وعشرون ســنة،

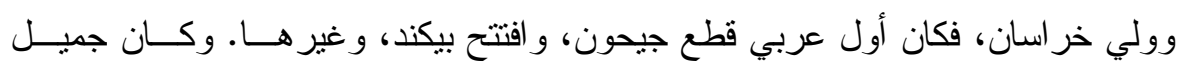

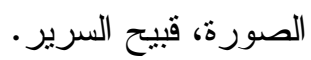

وقيل: كانت أمه مرجانة من بنات ملوك الفرس. قال أبو و ائل: دخلت عليه بالبــصرة وبــين

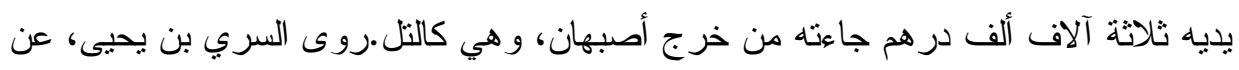

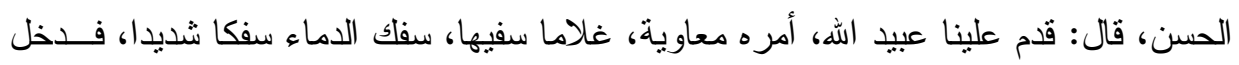

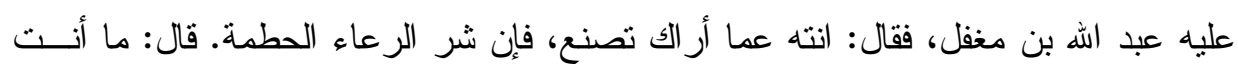

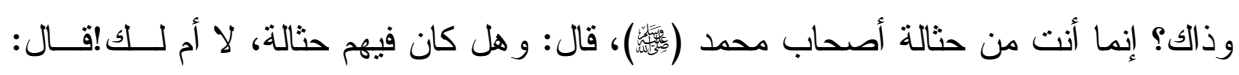

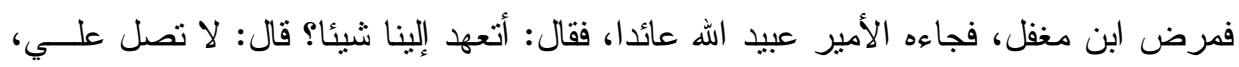

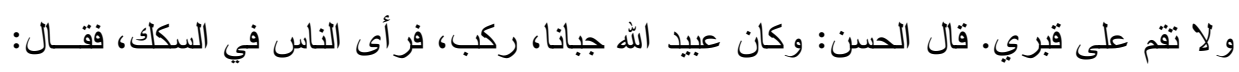

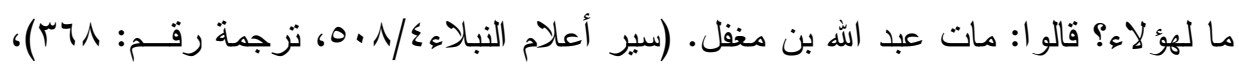

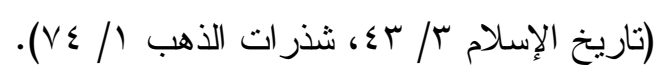


قال العظيم آبادي صاحب عون المعبود: (قال عبد السلام (ثهدت أبا برزة

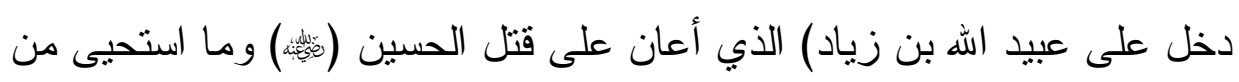
الله وكان و اليا على الكوفة من جهة يزيد. و المعنى أني أثهر على أبي برزة أنه دخل على أمير الكوفة عبيد اله بن زياد (فحدثي فلان) هذه مقولة عبد السلام ولم يكن عبد السلام حاضر المع أبي برزة فلم يسمع من أبي برزة نفسه ما جرى بين أبي برزة وبين عبيد الله بن زياد.

(في السماط) بكسر أوله أي الجماعة من الناس.و المراد جماعة كانو ال جلوسا عن جانبيه ويقال بين السماطين أي الصفين وقوله كان في السماط أي الصف من الناس.قال المنذري في إسناده رجل مجهول) أ.هــ('). أخرجه أبو داود في سننه، كتاب: السنة، باب: في الحوض، حديث رقم:

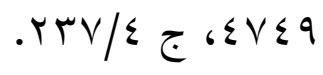

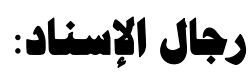

1- مسلم بن إبر اهيم الأزدي الفر اهيدي مو لاهم أبو عمرو البصري الحافظ روى عن عبد السلام بن شداد وجرير بن حازم و أبان بن يزيد العطار و غيرهم. وروى عنه: البخاري وأبو داود ومحمد بن يحيى القطعي وعبد بن حميد

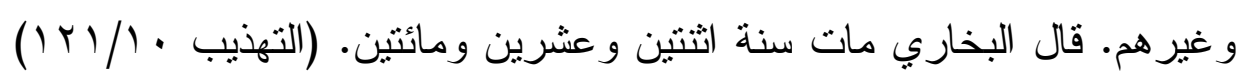
قال ابن حجر : ثقة مأمون مكثر عمي بأخرة من صغار التاسعة مات سنة اثثتين

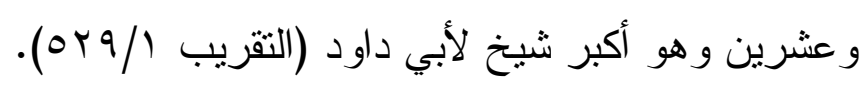

r- عبد السلام بن أبي حازم واسمه شداد العبدي القيسي أبو طالوت البصري روى: عن أنس وأبي برزة الأسلمي وغيرهما، وروى عنه أبه: أبو نعيم

$$
\text { (1) (1) عون المعبود ب ا (1).09. }
$$


ومحمد بن عبد الله الأنصاري ومسلم بن إير اهيم وغيرهم. (التهذيب ج/ جاب)

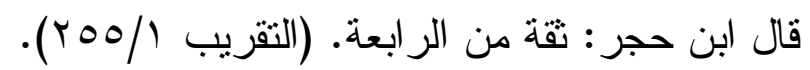
r- أبو برزة: اسمه نضلة بن عبيد أبو برزة الأسلمي صحابي مشهور

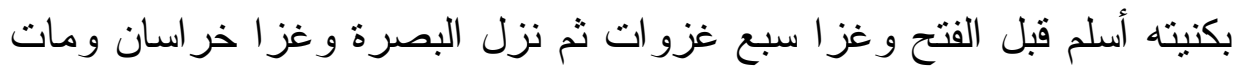

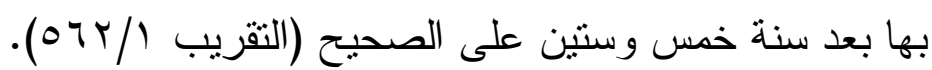

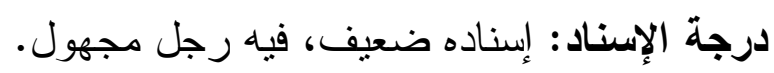

\section{الإطلب الرابع: وجود الموض الآن:}

الحوض مخلوق موجود الآن كما نشهد بذلك الروايات التالية. قال النووي التهات

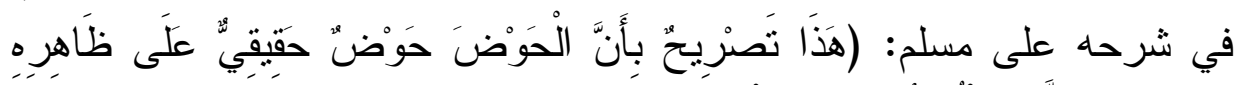

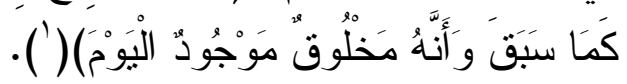

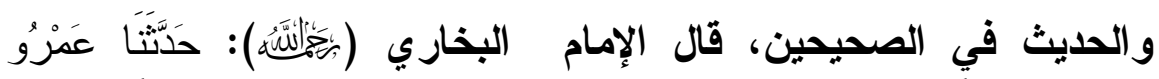

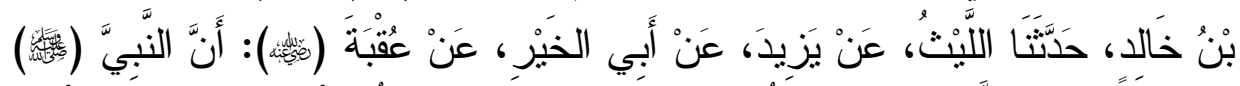

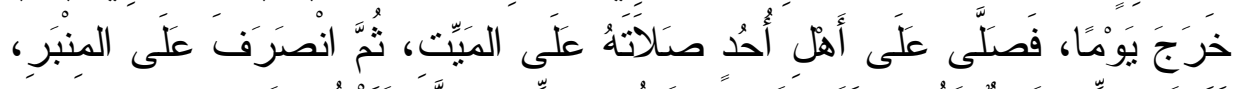

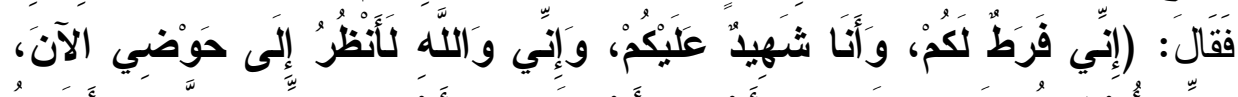

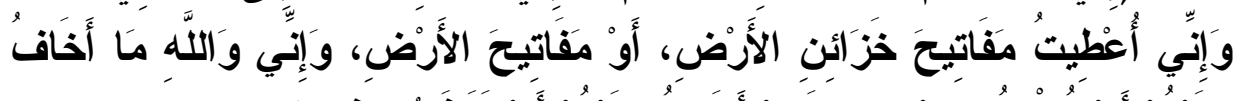

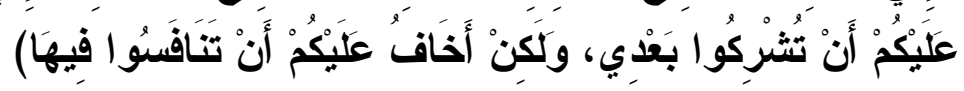

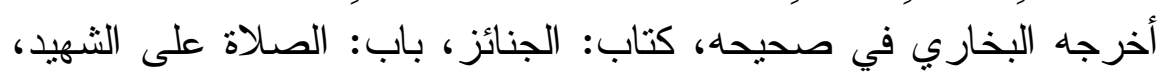

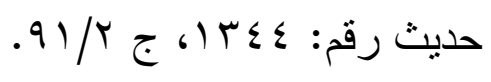

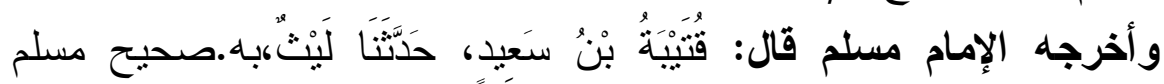

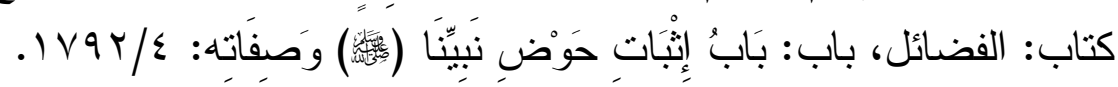

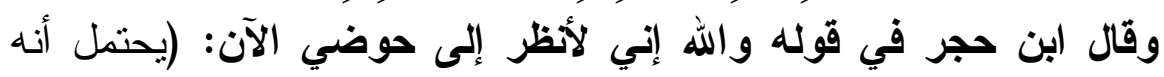
كثف له عنه لما خطب وهذا هو الظاهر ويحتمل أن بريد رؤية القلب)( (').

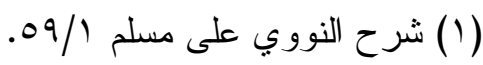

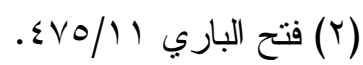

